〈Research Paper〉

\title{
Utilization of Bamboo Leaves as a New Resource of Natural Green Colorants
}

\author{
Younsook Shin ${ }^{\dagger}$, Arang Cho and Dong II Yoo ${ }^{1}$ \\ Department of Clothing and Textiles/Human Ecology Research Institute, Chonnam National University, Gwangju, Korea \\ ${ }^{1}$ Department of Polymer and Fiber System Engineering, Chonnam National University, Gwangju, Korea
}

(Received: November 22, 2012 / Revised: December 3, 2012 / Accepted: December 10, 2012)

\begin{abstract}
The objective of this study was to find an appropriate method and process for protecting the green color in bamboo leaves and subsequent extraction of the green colorants, chlorophyll. Various inorganic salts including cupric sulfate, ferric sulfate, and zinc chloride were employed as green color protectors. Accordingly, the effects of metal salts and treatment conditions on color protection were investigated to find appropriate protector and conditions. And also, the efficacy of bamboo colorants as a natural green dye was evaluated through dyeing and colorfastness tests. Antimicrobial activity of dyed fabrics was measured by shake flask method in terms of bacterial reduction rate using Staphylococcus aureus(ATCC 6538). On the basis of experimental results for stabilizing bamboo leaves colorants, it was confirmed that $\mathrm{Cu}$ was the most appropriate metal type considering dye uptake, photostability and light fastness, and its optimum concentration was $0.025 \%$. After the stabilization, the colorants were extracted efficiently at $\mathrm{NaOH}$ aqueous solution of $1.00 \%$. It was concluded that bamboo leave has a high potentiality as new resources to produce a natural green dye with antimicrobial functionality.
\end{abstract}

Keywords: bamboo leaves, chlorophyll, pretreatment, photostability, antimicrobial activity

\section{Introduction}

Bamboo exhibits attractive greenish color due to the abundant chlorophyll in culms as well as in leaves. But the green color on the bamboo culms fades away because of chlorophyll degradation easily by light, oxygen and enzymes ${ }^{1)}$.

The green color protection of bamboo had been widely studied to increase the economic value of bamboo products using green culms.

However, abundant bamboo leaves have not been utilized, except that young leaves made into bamboo tea recently in Korea.

We thought the bamboo leaves have a high potentiality for useful resource of natural green dye. In previous studies, several inorganic salts including chromates, nickel salts, and copper salts were used as protectors of green color of bamboo culms ${ }^{2,3)}$.

In addition to inorganic salts treatments, alkali pretreatment was necessary process for the protection of bamboo green color ${ }^{4}$.

${ }^{\dagger}$ Corresponding author: Younsook Shin (yshin@jnu.ac.kr) Tel.: +82-62-530-1341 Fax.: +82-62-530-1349

(C)2012 KSDF 1229-0033/2012-12/247-252
Paying attention on this point, the objective of this study was to find an appropriate method and process for protecting the green color in bamboo leaves and subsequent extraction of the green colorants. Various inorganic salts including cupric sulfate, ferric sulfate, and zinc chloride were employed as green color protectors.

Accordingly, the effects of metal salts and treatment conditions on color protection were investigated to find appropriate protector and conditions. And also, the efficacy of bamboo colorants as a natural green dye was evaluated through dyeing and colorfastness tests.

\section{Experimental}

\subsection{Materials}

Bamboo leaves of Phyllostachs nigra (Lodd) Munro var. henonis (Bean) Stapf in Damyang areas were collected, dried in the shade and kept in a refrigerator.

Reagents used were of first grades. For dyeing test, wool and microfiber nylon fabrics were obtained commercially (Table 1) 
Table 1. Specifications of fabrics

\begin{tabular}{ccccc}
\hline Fabric & Weave & Yarn count $\left.\mathbf{( w \mathbf { w }} / \mathbf{c m}^{\mathbf{2}}\right)$ & Weight $\left(\mathbf{g} / \mathbf{m}^{\mathbf{2}}\right)$ & Thickness $(\mathbf{m m})$ \\
\hline \hline Wool & plain & $28 \times 27$ & 102 & 0.25 \\
Microfiber nylon & plain & $50 \times 70$ & 62 & 0.02 \\
\hline
\end{tabular}

\subsection{Pretreatment and extraction}

Bamboo leaves $(50 \mathrm{~g})$ were boiled for $60 \mathrm{~min}$ to remove yellow colorants and subsequently treated with inorganic salts such as solution to protect green color of chlorophyll. Three inorganic salts used were $\mathrm{CuSO}_{4} \cdot 5 \mathrm{H}_{2} \mathrm{O}, \mathrm{FeSO}_{4} \cdot 7 \mathrm{H}_{2} \mathrm{O}$ and $\mathrm{ZnCl}_{2}$. The pretreated bamboo leaves were used to extract colorants in $\mathrm{NaOH}$ solution at $80^{\circ} \mathrm{C}$ for $1 \mathrm{hr}$ and this extraction process was repeated twice. Two extracts were mixed together, filtered, concentrated, quick frozen at $-80^{\circ} \mathrm{C}$ and frozen dried at $-50^{\circ} \mathrm{C}$.

\subsection{Dyeing and color evaluation}

Using colorant extracts, dyeing was carried out $100^{\circ} \mathrm{C}$ for $60 \mathrm{~min}$ at a liquor ratio of $1: 100$ using an infra-red automatic dyeing machine (Ahiba Nuance, Data Color International, USA), and rinsed for further evaluation. Dye uptake was assessed by measuring $\mathrm{K} / \mathrm{S}$ value at the maximum adsorption wavelength $(\lambda$ max; 400nm) using a Macbeth Coloreye 3100 spectrophotometer. CIELab coordinates (Illuminant $\mathrm{D}_{65} 10^{\circ}$ Observer) was measured with a Macbeth Coloreye 3100 spectrophotometer at $\lambda_{\max } . \mathrm{H} \mathrm{V/C}$ values were obtained from $\mathrm{L}^{*} \mathrm{a}^{*} \mathrm{~b}^{*}$ data using CIE Munsell conversion program. Absorbance of colorants extraction was measured using a UV-Vis spectrophotometer (Agilant 845, Agilant Technologies, Waldbronm, Germany).

\subsection{Colorfastness to light}

Light fastness was assessed in terms of color difference and color change against the appropriate Gray scale according to AATCC method 16-1998 with a Xenon Test Chamber (Q-Sun Xe-1-B, USA).

\subsection{Antimicrobial activity}

Antimicrobial activity of dyed fabrics was measured by shake flask method in terms of bacterial reduction rate. Staphylococcus aureus (ATCC 6538) was the bacteria used.

\section{Results and Discussion}

\subsection{Effect of pretreated metal type on colorants stability}

Figure 1 shows absorption spectra of colorant extracts at different metal pretreatment. Two peaks are observed at 400-420 $\mathrm{nm}$ and 630-660 nm, indicating yellow-green and green colors, respectively. Depending on metal type, peaks were varied slightly in similar color ranges. And so, their absorbance peaks were slightly different; extracts from no treated bamboo leaves at 415 and $638 \mathrm{~nm}, \mathrm{Cu}$ salt treated at 404 and $629 \mathrm{~nm}, \mathrm{Fe}$ salt treated at 400 and $656 \mathrm{~nm}, \mathrm{Zn}$ salt treated at 412 and $633 \mathrm{~nm}$. The extracted green colorants after pretreatment with metal salts were expected to form into metal-chlorophyll derivatives such as $\mathrm{Cu}^{-}$chlorophyll-Na, Fe-chlorophyll-Na, and $\mathrm{Zn}-$ chlorophyll-Na.

Chlorophyll is a stable colorant in nature, but it is degraded by surrounding environment such as oxygen, light, heat and acid when it is existed in extracts from

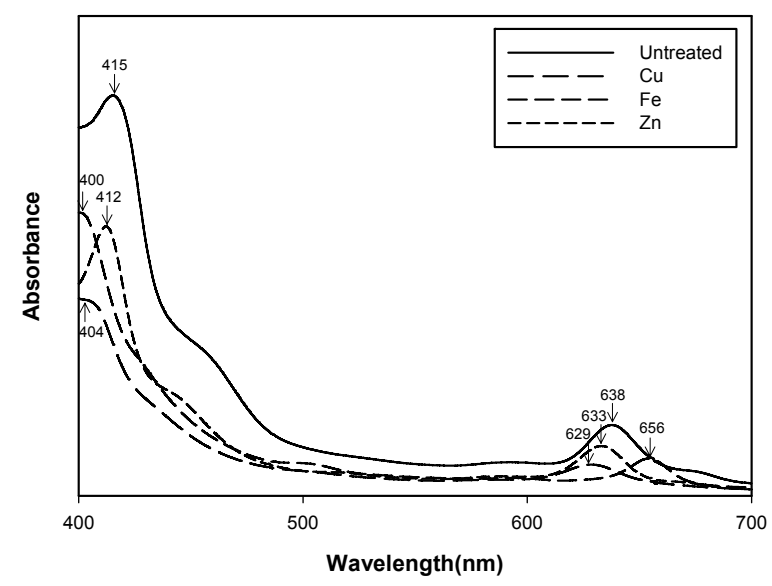

Figure 1. Visible absorption spectra of bamboo leaf extracts. 
plant tissue ${ }^{5)}$. The loss of green color of chlorophyll is caused by $\mathrm{pH}$ change as a result of turning $\mathrm{Mg}$ ion into $\mathrm{H}$ ion. Light stability of the extracts was evaluated in terms of absorbance retention, indicating colorant concentration, for 12 days under the artificial daylight (6500K) conditions including UV (Figure 2). Among inorganic metals, copper salt resulted in the highest stability of colorants, $80 \%$ of colorants were remained after 12 days of light exposure. Other metals resulted to retain $10-30 \%$ of colorants at $630^{-}$ $660 \mathrm{~nm}$. Fe salt treated extract was retained about $30 \%$ of absorbance after light exposure and, $\mathrm{Zn}$ salt treated extract showed about $10 \%$ of absorbance retention. Extracts from no pre-treated bamboo leaves retained about $20 \%$ of absorbance.

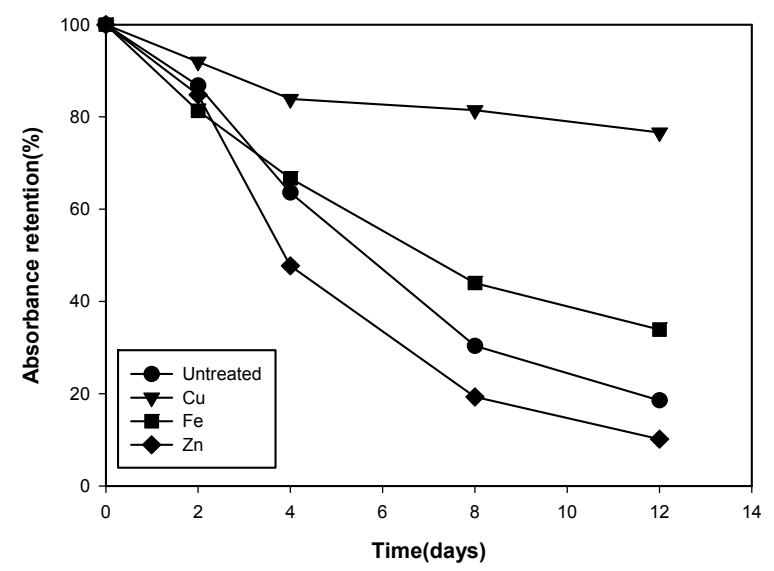

Figure 2. Light stability of colorants extracts pretreated with different metal salts.

\subsection{Effect of metal type on dyed color and light fastness}

Table 2 shows dyeing results using colorants extracts with different metal treatments respectively. Pretreatment was done at $0.05 \%$ of metal concentration, followed by extraction $1 \% \mathrm{NaOH}$ solution and then dyeing was carried out at $100^{\circ} \mathrm{C}$ for $60 \mathrm{~min}$. Without pretreatment, the colors of dyed wool and nylon fabrics were $0.6 \mathrm{GY}$ and $10.0 \mathrm{Y}$, indicating dark yellowish kaki color rather than green color, resulting higher $L^{*}$ value than pretreated samples. Among metal salts, Fe salt also produced yellowish color. The results confirmed that green color can be protected by $\mathrm{Cu}$ and $\mathrm{Zn}$ metal salts pretreatment on the basis of $\mathrm{a}^{*}$ value. Compared to $\mathrm{Zn}$ salt, $\mathrm{Cu}$ salt better protected green color of chlorophyll and produced more vivid green color to the dyed fabrics. Yellowness or blueness is expressed by coordinate a*, which is positive for yellow and negative for blue. The wool fabric dyed with $\mathrm{Cu}$ pretreated extract showed most greenish color, indicated by $-a^{*}$ value (7.76). The Nylon fabric also showed the most greenish color when dyed with $\mathrm{Cu}$ salt pre-treated extract, confirmed by $-\mathrm{a}^{*}$ value $(-13.87) . \Delta \mathrm{E}^{*}$ in Table 2 was calculated on the basis of undyed sample.

One of disadvantage of natural dye is low fastness to light. Chlorophyll of plants during storage degraded and green color faded away easily under light exposure.

Table 2. Color and colorfastness of dyed fabrics with colorants extracts after different metal pretreatment

\begin{tabular}{|c|c|c|c|c|c|c|c|c|}
\hline Fabric & Metal & Dyed color & H V/C & $\mathbf{L}^{*}$ & $a^{*}$ & $\mathbf{b}^{*}$ & $\Delta \mathbf{E}^{*}$ & Light fastness \\
\hline \multirow{4}{*}{ Wool } & Control & & $0.6 \mathrm{GY} \quad 3.9 / 3.1$ & 39.96 & -4.33 & 21.41 & 46.01 & 1 \\
\hline & $\mathrm{Cu}$ & & $3.4 \mathrm{GY} \quad 5.3 / 3.1$ & 53.93 & -7.76 & 20.80 & 32.97 & $2 / 3$ \\
\hline & $\mathrm{Fe}$ & & $9.9 Y \quad 4.5 / 3.1$ & 46.04 & -3.91 & 22.71 & 40.47 & 1 \\
\hline & $\mathrm{Zn}$ & & $1.7 \mathrm{GY} \quad 4.3 / 3.5$ & 44.39 & -6.48 & 23.87 & 42.64 & 1 \\
\hline \multirow{4}{*}{$\begin{array}{l}\text { Microfiber } \\
\text { nylon }\end{array}$} & Control & & $10.0 Y \quad 5.3 / 3.4$ & 54.10 & -4.12 & 24.96 & 47.92 & 1 \\
\hline & $\mathrm{Cu}$ & & $7.5 \mathrm{GY} \quad 6.2 / 3.5$ & 63.24 & -13.87 & 19.33 & 39.45 & $2 / 3$ \\
\hline & $\mathrm{Fe}$ & & $9.8 Y \quad 5.8 / 3.3$ & 59.47 & -4.12 & 24.29 & 43.08 & 1 \\
\hline & $\mathrm{Zn}$ & & $0.8 \mathrm{GY} \quad 5.0 / 3.5$ & 51.32 & -5.60 & 24.59 & 50.25 & 1 \\
\hline
\end{tabular}


$\mathrm{Cu}$ salt pretreatment before colorant extraction from bamboo leaves improved light fastness remarkably. Chlorophyll has $\mathrm{Mg}$ ion in the center of molecular structure and this $\mathrm{Mg}$ ion substitutes easily to $\mathrm{H}$ atom, resulting that green color changes to yellow and brown. More stable molecular structure was formed by replacing the magnesium ion in the porphyrin ring of chlorophyll of native form with divalent cations. This method has been used to keep green color in canned fruits and vegetables ${ }^{5}$. By $\mathrm{Cu}$ salt pretreatment, $\mathrm{Mg}$ ion is substituted to $\mathrm{Cu}$ ion, which has better stability. And bright green color is protected and shows improved light fastness.

On the basis of experimental results, it was confirmed that $\mathrm{Cu}$ salt was the most appropriate protector of green color considering dye uptake, photostability, and light fastness. Experiment for optimum pretreatment condition with $\mathrm{Cu}$ salt was carried out further.

\subsection{Effect of $\mathrm{Cu}$ salt concentration on green color protection}

Figure 3 shows absorption spectra of bamboo leaves extracts depending on the pretreatment concentration of $\mathrm{Cu}$ salt. Absorbance at $629 \mathrm{~nm}$ was decreased with increase $\mathrm{Cu}$ salt concentration.

Highest absorbance was obtained at $\mathrm{Cu}$ salt concentration of $0.025 \%$. The results indicated that the extracted color was more greenish at $0.025 \%$. So, its optimum concentration of $\mathrm{Cu}$ salt was $0.025 \%$.

To understand the influence of $\mathrm{Cu}$ salt concentration on green color protection and dye uptake, $\mathrm{Cu}$ salt

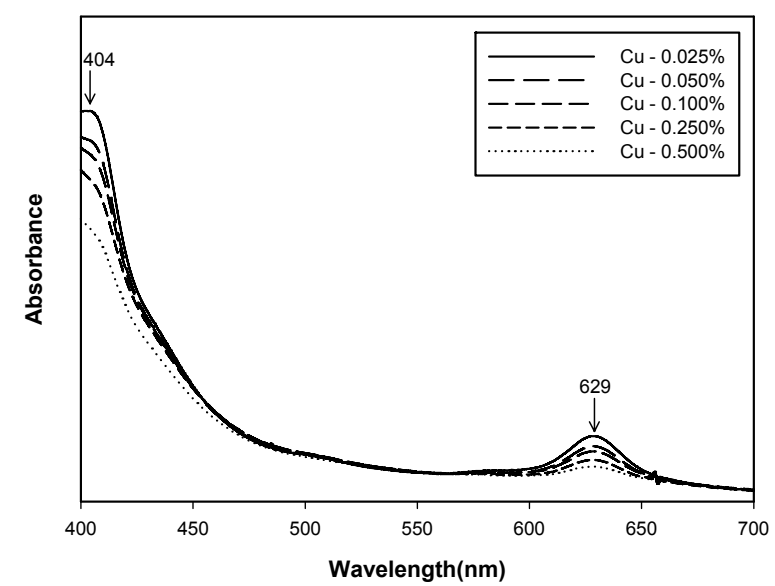

Figure 3. Visible absorption spectra of extracts from $\mathrm{Cu}$ salt pretreated bamboo leaves.

concentration was varied. Green colorants were extracted from the $\mathrm{Cu}$ salt pretreated bamboo leaves in alkaline $(1 \% \mathrm{NaOH})$ solution and wool fabrics were dyed with the extracts adjusting $\mathrm{pH} 7$ at $100^{\circ} \mathrm{C}$ for $60 \mathrm{~min}$. The results are presented in Table 3 .

The highest dye uptake was obtained at $0.025 \%$ of $\mathrm{Cu}$ salt concentration and thereafter it decreased with increasing $\mathrm{Cu}$ salt concentration. Accordingly, $-\mathrm{a}^{*}$ value was decreased with increasing $\mathrm{Cu}$ salt concentration. It is speculated that $\mathrm{Cu}$ salt may be existed in dipole form to make larger molecule at higher concentration and thereby, accessibility to chlorophyll was decreased. $\mathrm{Wu}$ et al. confirmed that green color( $-\mathrm{a}^{*}$ value $)$ of bamboo culms was protected efficiently at $0.5 \%$ of copper chloride, but $-\mathrm{a}^{*}$ value was decreased at higher than $0.5 \%$ of copper chloride ${ }^{1)}$. At $0.025 \%$ of $\mathrm{Cu}$ salt concentration, hue value $(6.4 \mathrm{GY})$ of dyed wool fabric indicated more greenish color.

Table 3. Effect of $\mathrm{Cu}$ salt concentration on the color of dyed wool

\begin{tabular}{ccccccc}
\hline Cu concen.(\%) & K/S value & Dyed color & Hue & $\mathbf{L}^{*}$ & $\mathbf{a}^{*}$ & $\mathbf{b}^{*}$ \\
\hline \hline 0.025 & 15.5 & & $6.4 \mathrm{GY}$ & 49.51 & -11.99 & 19.62 \\
0.050 & 12.0 & $3.4 \mathrm{GY}$ & 53.93 & -7.76 & 20.80 \\
0.100 & 9.0 & $1.8 \mathrm{GY}$ & 56.24 & -6.03 & 21.32 \\
0.025 & 7.5 & $9.2 \mathrm{Y}$ & 57.93 & -3.51 & 22.57 \\
0.500 & 6.3 & $6.7 \mathrm{Y}$ & 58.56 & -1.29 & 23.87 \\
\hline
\end{tabular}


With increasing $\mathrm{Cu}$ salt concentration, the hue values moved progressively toward more yellowish color. Accordingly, $0.025 \%$ of $\mathrm{Cu}$ salt concentration was the most effective to protect green color $\left(\mathrm{a}^{*}-11.99\right)$ and it resulted the best dye uptake (K/S 16.8).

The results confirmed that green color can be protected by metal salts pretreatment and $\mathrm{Cu}$ salt among metal salts produced more saturated green color to the dyed fabrics. Similar results were obtained on nylon fabrics.

\section{4 $\mathrm{NaOH}$ concentration effect on dye uptake and color}

Chlorophyll is not water soluble. Alkaline condition is needed to extract chlorophyll. To find more efficient extraction condition, colorants extraction was done with varied $\mathrm{NaOH}$ concentrations.

As shown in Table 4, dye uptake increased with the increase of $\mathrm{NaOH}$ concentration, indicating more colorants were extracted at higher $\mathrm{NaOH}$ concentration.

And, the hue of dyed wool fabrics moved from $3.9 \mathrm{GY}$ to $6.4 \mathrm{GY}$ with increasing $\mathrm{NaOH}$ concentration. The color of dyed wool was observed getting stronger green color as $\mathrm{NaOH}$ concentration increased up to $1.0 \%$.

Green color protection was considered more critical than getting high dye uptake in this study. The optimum concentration of $\mathrm{NaOH}$ for extraction was set $1.0 \%$. It is necessary that the balance between color and dye uptake should be considered for determining optimum condition.

\subsection{Antimicrobial activity}

Table 5 shows antimicrobial activity of the dyed fabrics. Wool and nylon fabrics dyed at 3\% colorants concentration exhibited above $90 \%$ and $99 \%$ reduction rate against Staphylococcus aureus (ATCC 6538), respectively. It has been known that extracts from bamboo leaves has functional properties such as antiaging, antibacterial, antivirus and so on ${ }^{(-8)}$.

Table 5. Bacterial reduction rates of dyed fabrics

\begin{tabular}{|c|c|}
\hline Fabrics & Staphylococcus aureus (ATCC 6538) \\
\hline Wool & $90.4 \%$ \\
\hline Nylon & $99.9 \%$ \\
\hline
\end{tabular}

In addition, the antimicrobial activity of green colorants prepared in this study is also attributed by $\mathrm{Cu}$ pretreatment. Recently, consumer's concern in health and wellbeing has been increased so that the functionalities of natural colorants are considered very important advantage ${ }^{7,9-11)}$. So, the antimicrobial functio -nality of green colorants prepared would be valuable advantage and it can be applied in various end uses including cosmetics and hygienic products as well as textiles.

\section{Conclusion}

Bamboo leaves was explored as new biomass resources for natural green dye for textiles. Metal salts including $\mathrm{Cu}, \mathrm{Fe}$, and $\mathrm{Zn}$ salts were pretreated for protecting green color before extraction of colorants.

Table 4. Effect of $\mathrm{NaOH}$ concentration on the color of dyed wool

\begin{tabular}{ccccccc}
\hline NaOH concen.(\%) & K/S value & H V/C & $\mathbf{L}^{*}$ & $\mathbf{a}^{*}$ & $\mathbf{b}^{*}$ & Dyed color \\
\hline \hline 0.25 & 6.75 & $3.9 \mathrm{GY}$ & $6.0 / 3.2$ & 61.59 & 8.54 & 21.96 \\
0.50 & 12.00 & $6.0 \mathrm{GY}$ & $5.2 / 3.6$ & 53.77 & 11.61 & 20.80 \\
0.75 & 15.50 & $6.3 \mathrm{GY}$ & $4.9 / 3.5$ & 50.45 & 11.96 & 19.94 \\
1.00 & 16.50 & $6.4 \mathrm{GY}$ & $4.8 / 3.5$ & 49.51 & 11.99 & 19.62 \\
1.50 & 15.25 & $6.4 \mathrm{GY} 4.9 / 3.5$ & 50.42 & 11.83 & 19.73 & \\
\hline
\end{tabular}


Among them, $\mathrm{Cu}$ imparted the best photostability and thus efficient protection of green color of bamboo leaves. And more saturated green color was produced on wool and nylon fabrics with $\mathrm{Cu}$ salt pretreated extracts. The optimum concentration of $\mathrm{Cu}$ salt for pretreatment was $0.025 \%$. The colorants extraction of the $\mathrm{Cu}$ salt pretreated bamboo leaves was carried out efficiently at $1.00 \% \mathrm{NaOH}$ solution.

Wool and nylon fabrics dyed at 3\% colorants concentration exhibited above $90 \%$ and $99 \%$ reduction rate against Staphylococcus aureus (ATCC 6538), respectively.

In conclusion, bamboo leaves has a high potentiality as a new resource to produce a natural green colorants with antimicrobial functionality.

\section{References}

1. J. H. Wu, M. J. Chung, and S. T. Chang, Green Color Protection of Bamboo Culms using Onestep Alkali Pretreatment-free Process, J. Wood Science, 51(6), 622(2005).

2. S. T. Chang, J. H. Wu, and T. F. Yeh, Effects of Chromate-phosphate Treatment Process on the Green Color Protected of Ma Bamboo, J. Wood Science, 48(3), 227(2002).

3. J. H. Wu, S. Y. Wu, T. Y. Hsieh, and S. T. Chang, Evaluation of the Effectiveness of Alcohol-borne Reagents on the Green Colour Protection of Makino Bamboo (Phyllostachys makino), Polymer Degradation and Stability, 78(2), 379 (2002).

4. S. T. Chang and T. F. Yeh, Effects of Alkali Pretreatment on Surface Properties and Green Color
Conservation of Moso Bamboo (Phyllostachys pubescens M.), Holzforschung, 54(5), 487(2000).

5. P. Senklang and P. Anprung, Optimizing Enzymatic Extraction of $\mathrm{Zn}$-Chlorophyll Derivatives from Pandan Leaf using Response Surface Methodology, J. Food Processing and Preservation, 34(5), 759(2010).

6. G. Xu, H. Zhang and J. H. Dong, Studies on Superoxide and Hydroxyl Radical Scavenging Capacity of Bamboo Extracts, J. of Nutrition, 23(1), 79(2001)

7. J. S. Lee and G. E. Jeong, A Study on Natural Dye Having the Effects on the Atopic Dermatitis (Part I )-Bamboo Extract-, Textile Coloration and Finishing(J. Korean Soc. Dye. and Finish.), 24(3), 189(2012).

8. R. W. Young and J. S. Beregi, Use of Chlorophyllin in the Care of Geriatric Patients, $J$. American Geriatric Society, 28(1), 46(1980).

9. Y. J. Jang, Y. H. Choi, H. M. lee, M. S. Tak, W. S. Lyoo and J. Jang, Color Deepening and Antimicrobial Finish in the Dyeing of Cotton Fabrics using Rhus verniciflua Extract, Textile Coloration and Finishing(J. Korean Soc. Dye. and Finish.), 23(1), 28(2011).

10. E. S. Im and H. S. Lee, A Study on Function of Natural Dyeing with Cotton Fabrics Using Jeju scoria, Textile Coloration and Finishing(J. Korean Soc. Dye. and Finish.), 23(3), 179(2011).

11. J. S. Lee and H. J. Woo, A Study on Natural Dye Having the Effects on the Atopic Dermatitis (Part II)-Pine Needles Extract-, Textile Coloration and Finishing(J. Korean Soc. Dye. and Finish.), 24(3), 196(2012). 